\title{
Surface Reactions on Thin Layers of Silane Coupling Agents
}

\author{
Dirk G. Kurth and Thomas Bein* \\ Department of Chemistry, Purdue University, West Lafayette, Indiana 47907
}

Received February 3, 1992. In Final Form: June 23, $1993^{\circ}$

\begin{abstract}
The reactivity of immobilized functional groups in thin layers of (3-aminopropyl)triethoxysilane (APS), (3-mercaptopropyl)trimethoxysilane, (3-bromopropyl)trimethoxysilane, and (8-bromooctyl)trimethozysilane on oxidized aluminum substrates was studied with reflection-adsorption infrared spectroscopy (RAIR), optical ellipsometry and contact-angle measurements. Mass changes on the surface associated with the surface-confined reactions were measured with the quartz crystal microbalance (QCM). Single layers of (3-aminopropyl)triethoxysilane on oxidized aluminum react with chlorodimethylsilane to give $\left[(-\mathrm{O})_{3} \mathrm{Si}_{(}\left(\mathrm{CH}_{2}\right)_{3} \mathrm{NH}_{2}+\mathrm{SiMe}_{2} \mathrm{H}\right] \mathrm{Cl}^{-}$and single layers of (3-mercaptopropyl)trimethoxysilane on oxidized aluminum react with phenylmercury hydroxide to give $\left[(-0)_{3} \mathrm{Si}\left(\mathrm{CH}_{2}\right)_{3} \mathrm{SHgPh}\right]$, while no substitution reaction of (3-bromopropyl)trimethoxysilane and (8-bromooctyl)trimethoxysilane monolayers occurred with cyanide. Films of APS were further utilized to immobilize pepsin. It is discussed to which extent known reactions from solution can be transferred to interface reactions.
\end{abstract}

\section{Introduction}

In recent years monomolecular assemblies on solid surfaces have attracted growing attention. ${ }^{1}$ The focus of these studies has been on thiols immobilized on gold surfaces ${ }^{2}$ (self-assembling monolayers, SAM's), silane coupling agents (SCA) on various hydroxylated surfaces, such as silicon, ${ }^{3}$ and Langmuir-Blodgett films. ${ }^{4}$ Reflection-absorption infrared spectroscopy (RAIR) in particular permits the investigation of thin films on an almost routine basis. ${ }^{5}$ Other valuable tools for thin film studies are angle resolved X-ray photoelectron spectroscopy (XPS), ellipsometry, and contact-angle measurements. ${ }^{6}$ In this paper we wish to report about another promising technique for thin film studies, the quartz-crystal microbalance (QCM). Piezoelectric crystals are extremely sensitive mass detectors. ${ }^{7}$ The fundamental frequency of the quartz crystal depends on the total mass of the crystal element with its electrodes and the deposited mass on the electrodes. The method explored here is based on measuring the shift of the resonance frequency of the QCM upon mass adsorption during a reaction on the electrode surface of the crystal. The mass change upon adsorption of the silane coupling agent is a direct measure of the number density of functional groups immobilized on the

* Author for correspondence.

- Abstract published in Aduance ACS Abstracts, August 15, 1993.

(1) Bain, C.; Whitesides, G. M. Adv. Mater. 1989, 28, 506.

(2) (a) Nuzzo, R.; Korenic, E.; Dubois, L. J. Phys. Chem. 1990, $93,767$.

(b) Bain, C.; Troughton, E.; Tao, Y.; Evall, J.; Whitesides, G. M.; Nuzzo,

R. J. Am. Chem. Soc. 1989, 111, 321. (c) Troughton, E.; Bain, C. Whitesides, G. M.; Nuzzo, R.; Allara, D.; Porter, M. Langmuir 1988, 4, 365. (d) Strong, L.; Whitesides, G. M. Langmuir 1988, 4, 546.

(3) (a) Wasserman, S. R.; Tao, Y.; Whitesides, G. M. Langmuir 1989 5, 1074. (b) Gun, J.; Sagiv, J. J. Colloid Interface Sci. 1986, 112, 457. (c) Pomerantz, M.; Segmuller, A.; Netzer, L.; Sagiv, J. Thin Solid Films $1985,132,153$.

(4) (a) Gaines, G. L. Insoluble Monolayers at Liquid Gas Interfaces: Wiley: New York, 1983; Vol. 99. (b) Roberts, G. Langmuir-Blodgett Films; Plenum Press: New York, 1990.

(5) (a) Allara, D.; Nuzzo, R. Langmuir 1985, 1,45. (b) Allara, D.; Nuzzo,

R. Langmuir $1985,1,52$.

(6) (a) Wasserman, S.; Whitesides, G. M. Tidswell, I.;Ocko, B.; Pershan, P.; Axe, J. J. Am. Chem. Soc. 1989, 111, 5852. (b) Bain, C.; Whitesides, G. M. J. Phys. Chem. 1989, 93, 1670. (c) Nuzzo, R.; Dubois, L.; Allara, D. J. Am. Chem. Soc. 1990, 112, 558. (d) Dubois, L.; Zergarski, B.; Nuzzo, R. J. Am. Chem. Soc. 1990, 112, 570. (e) Holmes-Farley, S.; Reamey, R.

H.; McCarthy, T. J.; Deutsch, J.; Whitesides, G. M. Langmuir 1985, 1, 725 .

(7) (a) Ward, M.; Buttry, D. Science, 1990, 249, 1000. (b) Ballantine, D. S.; Wohltjen, H. Anal. Chem. 1989, 61, 704A. surface. The mass change after subsequent reactions gives the chemical yield of the reaction occurring at the surfaceambient interface.

The QCM has been used extensively in analytical chemistry, surface science, for thin film deposition control and electrochemistry. ${ }^{8}$ The adsorption kinetics and reactions of thiols on gold have been studied with piezoelectric devices. ${ }^{9}$ Despite the nonspecific nature of the QCM response, the low cost, the rigidity, and the ease of operation make it a valuable tool among the surface analytical instruments.

One aspect of our research is concerned with the chemistry of the immobilized molecule on a surface. The interactions of an immobilized functional group with a reagent from the ambient can differ from well-known reactions in solution. The differences can be attributed to factors such as transport limitations, solvation effects, charge and dipole effects, and steric constraints. Chemical accessibility becomes an important factor for the reactivity of surface-immobilized groups. As a result, the outcome of a reaction depends on the reactivity and accessibility of the functional group in the interface toward the reagents from the ambient phase. A few studies on the reactivity of surface immobilized functional groups have been reported to date. ${ }^{10}$ These studies indicate that chemical reactions known in solution are transferable to reactions on a surface. ${ }^{11}$

In this article we report about the reactions of monolayers of (3-aminopropyl)triethoxysilane (APS) with chlorodimethylsilane, (3-mercaptopropyl)trimethoxysilane (MPS) with phenylmercury hydroxide, and the reactions of (3-bromopropyl)trimethoxysilane (BPS) and (8-bromooctyl)trimethoxysilane (BOS) with cyanide. We have found that reproducible formation of very thin films is

(8) (a) Applications of the Quartz-Crystal Microbalance; Lu, C., Czanderma, A. W., Eds.; Methods and Phenomena Vol. 7, Elsevier Science Publishing: New York, 1984; Vol. 7. (b) Buttry, D. Applications of the Quartz-Crystal Microbalance to Electrochemistry, in press.

(9) (a) Thomas, R. C.; Sun, L.; Crooks, R. M.; Ricco, A. J. Langmuir 1991, 7, 620. (b) Sun, L.; Thomas, R. C.; Crooks, R. M.; Ricco, A. J. J. Am. Chem. Soc. 1991, 113, 8550.

(10) (a) Tillman, N.; Ulman, A.; Elman, J. F. Langmuir 1989, 5, 1020. (b) Tillman, N.; Ulman, A.; Elman, J. F. Langmuir 1989, 5, 101. (c) Haller, I. J. Am. Chem. Soc. 1978, 100, 8050. (d) Xu, C.; Sun, L.; Kepley, L. J., Crooks, R. M.; Ricco, A. J. Anal. Chem. 1993, 65, 2102.

(11) Kurth, D.; Bein, T. Angew. Chem., Int. Ed. Engl. 1992, 31, 336. 
possible by vapor adsorption of the SCA on the substrate at room temperature. ${ }^{12}$

The functional groups chosen offer a diverse chemistry for further interface modifications. ${ }^{13}$ Both amines and mercaptans play an important role in the surface attachment of biological molecules, such as enzymes. ${ }^{14}$ The immobilization of enzymes has gained considerable attention for technical processes and commercial applications of biochemically catalyzed reactions. ${ }^{15}$ Recently, immobilized antibodies have shown great potential as biochemical sensors. ${ }^{16}$ The simulation of in vivo conditions in model systems of immobilized enzymes in surfaceanchored lipid membranes opens new ways toward elucidating the diversity of structure and reactivity in such systems. We wish to report the immobilization of pepsin on monomolecular layers of APS via the carbodiimide method (DCC).

\section{Results and Discussion}

The QCM provides an easy means to weigh the mass increase on the surface of the electrode during a reaction, both in situ and ex situ. ${ }^{17}$ The relation between the frequency change, $\delta f$, and the mass adsorbed, $\delta m$, has been derived by Sauerbrey ${ }^{18}$

$$
\delta f=-2 \frac{f_{0}^{2} \delta m}{\mathrm{~A}(\rho \mu)^{1 / 2}} \text { and } \delta m=-c_{\mathrm{f}} \delta f
$$

where $A$ denotes the piezoelectric active area, $f_{0}$ the fundamental frequency, $\mu$ the shear modulus, $\rho$ the density of quartz, and $c_{\mathrm{f}}$ the sensitivity factor. For a $9-\mathrm{MHz}$ crystal operated at its fundamental frequency the sensitivity factor $c_{\mathrm{f}}$ is $5.4 \mathrm{ng} \mathrm{Hz} \mathrm{cm}^{-2}$. It can be seen from eq 1 that the mass-frequency relation is linear. If the change in frequency is less than about $2 \%$ of the fundamental frequency caused by the mass loading and if the mass is equally distributed across the electrode surface, eq 1 can be used, as has been demonstrated by the work of Jones and Mieure ${ }^{19}$ and Ward. ${ }^{20}$ A molecular layer is very thin compared to the wavelength of the shear wave in the resonator; the adsorbed layer is thus located at the antinode of the shear wave. Therefore, the adsorbed layer should experience no significant shear deformation, and its viscoelastic properties should have no influence on the measurement.

The sensitivity of the QCM was determined during this study by underpotential deposition of a monolayer of copper. ${ }^{21}$ The experimental sensitivity factor, $c_{f}$, was determined to be 5.10. The sensitivity factor, $c_{\mathrm{f}}$, derived from eq 1 is 5.38. The total fluctuation in the frequency is typically better than $2 \mathrm{~Hz}$. For a normal distribution $95 \%$ of all values fall within two standard deviations of the average value. The uncertainty of the mass deter-

(12) Kurth, D.; Bein, T. J. Phys. Chem. 1992, 96, 6707

(13) March, J. Advanced Organic Chemistry, 3rd ed.; John Wiley \& Sons: New York, 1985.

(14) Hartmeier, W. Immobilized Enzymes; Springer Verlag: Berlin, 1986.

(15) Wingard, L. B.; Berezin, I.; Klyosov, A. A. Enzyme Engineering; Plenum Press: New York. 1980.

(16) (a) Guilbault, G. Handbook of Enzymatic Methods of Analysis; Schwartz, M., Ed.; Marcel Dekker: New York, 1976. (b) Ebersole, R. C. Ward, M. D. J. Am. Chem. Soc. 1988, 110, 8623.

(17) (a) Melroy, O.; Kanazawa, K.; Gordon, J. G.; Buttry, D. Langmuir 1986, 2, 697. (b) Mieure, J.; Jones, J. Talanta 1968, 16, 149.

(18) Sauerbrey, G. Z. Phys. 1959, 155, 206.

(19) Jones, J. L.; Mieure, J. P. Anal. Chem. 1969, 41, 485.

(20) Ward, D. M.; Delawski, E. J. Anal. Chem. 1991, 63, 886.

(21) (a) Deakin, M. R.; Melroy, O. J. Electroanal. Chem. 1988, 239, 321. (b) Bruckenstein, S.; Swathirajan, S. Electrochim. Acta 1985, 30 851 . mination is thus approximately $10 \mathrm{ng} / \mathrm{cm}^{2} ;$ a film $1 \mathrm{~nm}$ thick with a density of $1 \mathrm{~g} / \mathrm{cm}^{3}$ has a weight of $100 \mathrm{ng}$. The QCM can thus detect $10 \%$ of that layer with a $95 \%$ confidence. The surface roughness of the quartz crystals used was taken into account for the calculations of the surface loading. The surface roughness was determined from nitrogen sorption measurements.

\section{Film Formation}

Monolayer of (3-Mercaptopropyl)trimethoxysilane (MPS). We found that adsorption of MPS on oxidized aluminum substrates from aqueous solution results in poorly defined multilayer films. Different solvent mixtures and conditions were explored. Films prepared by adsorption from solution were typically more than $20 \AA$ thick after thorough rinsing. This is attributed to the oligomerization of MPS in solution and the subsequent adsorption of these particles on the surface. Because of the poor definition of the films, the RAIR spectra show broad and asymmetric peaks. 22

The adsorption of MPS vapor on oxidized aluminum in a dry nitrogen atmosphere at room temperature results in a physisorbed film, which is removed by evacuation. (The frequency change of the $\mathrm{QCM}, \delta f$, is zero and no change of the ellipsometric angles $\Delta$ and $\psi$ is observed.) In contrast to the amine group in APS the mercapto group does not affect the surface anchoring reaction. ${ }^{23}$ Vapor adsorption followed by heating at $80^{\circ} \mathrm{C}$ under dry nitrogen results in one to three MPS layers, as determined by the QCM experiment and ellipsometry.

However, if an aqueous MPS solution is used to generate the vapors, monomolecular films are formed reproducibly.

The transmission IR spectra of the aqueous MPS solutions show the decay of the bands for the methoxy groups and changes in the $\mathrm{Si}-\mathrm{O}-\mathrm{Si}$ stretching region, indicating hydrolysis and polymerization reactions. We conclude that vapors of prehydrolyzed MPS, formed in solution, are adsorbed on the surface, followed by the condensation reaction with the surface hydroxyl groups. The vapor phase adsorption and subsequent evacuation results in a stable frequency shift of $30 \pm 2 \mathrm{~Hz}$, which is equivalent to a chemisorbed monolayer (see below). The excess physisorbed mass is desorbed by evacuation. Once a monolayer is adsorbed on the surface and all the adsorption sites are occupied, apparently no further chemisorption takes place. Figure 1 shows the frequency response of the QCM for the vapor adsorption of neat MPS vapors and prehydrolyzed MPS vapors. The adsorption of APS is shown for comparison.

Figure 2 shows the RAIR spectrum of an MPS monolayer on an oxidized aluminum substrate. Table I summarizes the peak assignments and positions. The RAIR spectrum shows a band around $1114 \mathrm{~cm}^{-1}$ for the $\mathrm{Si}-\mathrm{O}-\mathrm{Si}$ stretch. ${ }^{24}$ Monomeric MPS shows a corresponding band at $1091 \mathrm{~cm}^{-1}$ in the transmission IR spectrum. The bands at 1191 and at $2841 \mathrm{~cm}^{-1}$ and the shoulder around $2960 \mathrm{~cm}^{-1}$ are associated with the $\mathrm{CH}$ deformation and stretching modes of unhydrolyzed $-\mathrm{OCH}_{3}$ groups. The presence of the methoxy modes indicates that the MPS film is not completely hydrolyzed and cross-linked. If the film, consisting of a mixture of possible species, is represented

(22) Kurth, D.; Bein, T. Unpublished results.

(23) Kurth, D.; Bein, T. In preparation.

(24) (a) Anderson, D. Analysis of Silicones; Smith, A., Ed.; John Wiley \& Sons: New York, 1974; Chapter 10. (b) Richards, R. E.; Thompson, H. W. J. Chem. Soc. 1949, 124. (c) Smith, A. L. Spectrocim. Acta 1960, 16,87 . Anomalous dispersion can contribute to this shift. 


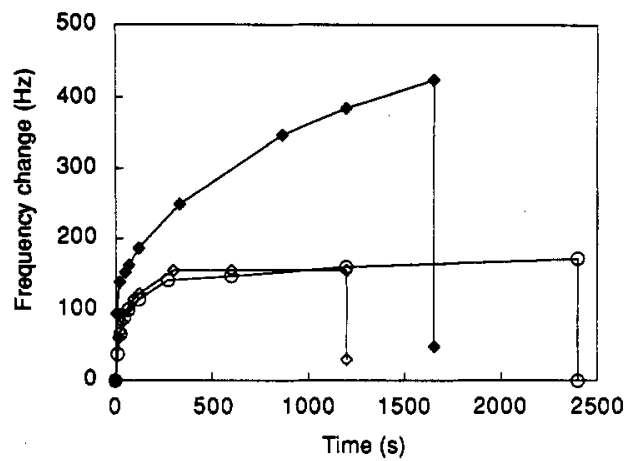

Figure 1. Real-time QCM response obtained for the adsorption of APS and MPS on oxidized aluminum. The vapor adsorbed MPS layer is removed by evacuation $(0, \delta f=0)$. APS forms a chemisorbed layer $(\diamond, \delta f=48 \mathrm{~Hz})$. If MPS is prehydrolyzed, the adsorbed layer remains bonded to the surface after evacuation $(\diamond, \delta f=30 \mathrm{~Hz})$. The final mass change is equivalent to a single layer in both cases (APS, $112 \mathrm{ng} / \mathrm{cm}^{2}, 8.6 \times 10^{-10} \mathrm{~mol} / \mathrm{cm}^{2} ; \mathrm{MPS}$, $\left.71 \mathrm{ng} / \mathrm{cm}^{2}, 5.3 \times 10^{-10} \mathrm{~mol} / \mathrm{cm}^{2}\right)$.
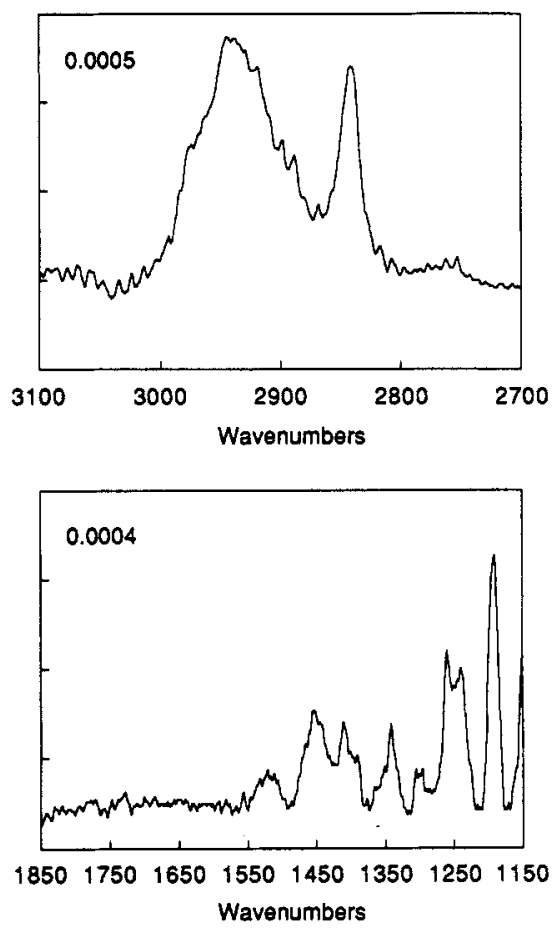

Figure 2. RAIR spectrum of an MPS monolayer on oxidized aluminum.

by $\mathrm{HS}\left(\mathrm{CH}_{2}\right)_{3} \mathrm{Si}(\mathrm{OMe})$ species on the surface, the calculated mass change is equivalent to $3.2 \pm 0.2$ molecules per $\mathrm{nm}^{2}$ (after correction for surface roughness), with an average surface area of $30 \AA^{2}$ per MPS molecule. ${ }^{25}$ This corresponds to approximately full surface coverage, based on the spatial requirements of the surface-attached species. The thickness of $9 \pm 1 \AA$, determined with ellipsometry, matches with the projection of an extended molecular chain on the surface normal and is in agreement with a single layer.

The positions of the $\mathrm{CH}$ stretching and deformation vibrations are similar to the transmission IR data. ${ }^{26}$ The $\mathrm{CH}$ stretching bands of the propyl group and the asym-

(25) Because of the bonding mechanism of SCA on hydroxylated surfaces, it is difficult to determine the exact composition of the surfaceadsorbed species. The surface species present could have zero, one, or two alkoxy groups. However, RAIR spectroscopy shows the presence of alkoxy groups and partial condensation of the siloxane moiety, which has led us to suggest a tentative average of one remaining alkoxy group. This was discussed in more detail in refs 11 and 12.
Table I. Band Positions and Assignments for MPS

\begin{tabular}{|c|c|c|}
\hline position $\left(\mathrm{cm}^{-1}\right)$ & assignment $t^{a}$ & lit. \\
\hline $\begin{array}{l}2960 \\
2938 \\
2841 \\
1455 \\
1440 \\
1412\end{array}$ & $\begin{array}{l}-\mathrm{OCH}_{3}, \text { asym str } \\
-\mathrm{CH}_{2}-\text { str (sym and asym) } \\
-\mathrm{OCH}_{3}, \text { sym str, } \mathrm{r}^{+}, \| \mathrm{O}-\mathrm{Me} \text { bond } \\
-\mathrm{OCH}_{3} \text {, def } \delta(\pi) \\
-\mathrm{CH}_{2} \text { def (shoulder) } \\
-\mathrm{Si}_{-}-\mathrm{CH}_{2}-\text {, def (sci) } \delta(\pi) \text { ip } \perp \\
\text { SiCC-plane }\end{array}$ & $\begin{array}{l}2955^{28} \\
\text { ref } 26 \\
2840^{24} \\
1460^{26} \\
\text { ref } 26 \\
1410-20^{24}\end{array}$ \\
\hline $\begin{array}{l}1341 \\
1306\end{array}$ & $-\mathrm{OCH}_{3}$, def $\delta(\pi)$ & $1340^{28 \mathrm{c}}$ \\
\hline 1260 & $\begin{array}{l}-\mathrm{Si}-\mathrm{CH}_{2}-\text {, def (wag) } \delta(\pi) \text { op } \\
\quad \text { SiCC-plane }\end{array}$ & $1255^{24}$ \\
\hline $\begin{array}{l}1240 \\
1191 \\
1114\end{array}$ & $\begin{array}{l}-\mathrm{OCH}, \text { def } \delta(\pi) \\
-\mathrm{OCH}_{3}, \text { def (rock) } \delta(\pi) \\
\text {-Si-O-C- } \\
-\mathrm{Si}-\mathrm{O}-\mathrm{Si}-\end{array}$ & $\begin{array}{l}1240-50^{26} \\
1190^{24} \\
\text { ref } 24\end{array}$ \\
\hline
\end{tabular}

a Nomenclature: \|, dipole moment parallel; $\perp$, dipole moment perpendicular, str, stretch; def, deformation; sym, symmetric; asym, asymmetric; wag, wagging; sci, scissoring; rock, rocking; ip, in-plane; op, out of plane; $\mathrm{r}_{\mathrm{a}}$, asym $\mathrm{CH}$-str ip $\left(\mathrm{CH}_{3}\right) ; \mathrm{r}_{\mathrm{b}}$, asym $\mathrm{CH}$-str op $\left(\mathrm{CH}_{3}\right) ; \mathrm{r}^{+}$, sym CH-str; d- $\mathrm{d}^{-}(\pi)$, asym $\mathrm{CH}-\operatorname{str}\left(\mathrm{CH}_{2}\right) ; \mathrm{d}^{+}(\pi)$, sym CH-str $\left(\mathrm{CH}_{2}\right) ; \delta(\pi), \mathrm{CH}_{2}$ def.

metric stretch of the methoxy group fall together to one broad peak at $2938 \mathrm{~cm}^{-1}$. The S-H stretch is not observed, because of its low absorption coefficient. The $-\mathrm{CH}_{2}$ scissoring vibration at $1412 \mathrm{~cm}^{-1}$ is of low relative intensity. The transition moment of this mode is in the $\mathrm{CH}_{2}$ plane and perpendicular to the propyl chain. Based on the surface selection rules it can be concluded that the weak intensity is due to an upright oriented propyl chain. This is consistent with the high intensity of the $\mathrm{Si}-\mathrm{CH}_{2}$ wagging band at $1260 \mathrm{~cm}^{-1}$. The transition moment of this mode is perpendicular to the $-\mathrm{CH}_{2}$ - plane. An approximately vertical orientation of the propyl chain is in good agreement with the film thickness of $9 \pm 1 \AA$. The contact angle of $57^{\circ}$ is consistent with a moderately polar surface where the mercapto group is oriented upward. ${ }^{27}$

The above data show that vapor adsorption from an aqueous MPS solution results in layers of approximately monolayer coverage.

Monolayer of (3-Aminopropyl)triethoxysilane (APS). A detailed study on the formation of APS monoand multilayers is reported elsewhere. ${ }^{28}$ In the present work, APS films were prepared by vapor phase adsorption, similar to the MPS experiments. Adsorption of neat APS vapors results in a chemisorbed layer and a physisorbed phase, which can be removed by evacuation (Figure 1). The RAIR spectrum of an APS monolayer is shown in Figure 3. Table II summarizes the peak positions and assignments. ${ }^{29}$ The thickness of this sample was determined to be $6 \pm 1 \AA$, which is consistent with a single layer.

The two bands at 1089 and $1118 \mathrm{~cm}^{-1}$ are assigned to $\mathrm{Si}-\mathrm{O}$ and $\mathrm{Si}-\mathrm{O}-\mathrm{C}$ stretching modes. ${ }^{24}$ The presence of the shoulder around $2970 \mathrm{~cm}^{-1}$ is assigned to the asymmetric methyl stretch $(-\mathrm{OEt}) .{ }^{24,26}$ These data indicate that the film consists of oligomeric siloxane networks.

In APS monolayers, prepared by vapor phase adsorption (method I), the aminopropyl group is found in two dominant arrangements. In the presence of remaining ethoxy groups the amine undergoes hydrogen bonding as indicated by RAIR spectroscopy. The surface loading,

(26) (a) Bellamy, L. J. The Infrared Spectra of Complex Molecules, 3rd ed.; Chapman and Hall: London, 1975. (b) Bellamy, L. J. Advances in Infrared Group Frequenices, 2nd ed.; Chapman and Hall: London, 1980. (c) Nakanishi, K.; Solomon, P. Infrared Absorption Spectroscopy, 2nd ed.; Holden-Day, Inc.: San Francisco, CA, 1977.

(27) Lee, L. H. J. Colloid Surf. Sci. 1968, 27, 751.

(28) Kurth, D.; Bein, T. In preparation.

(29) Chiang, C.; Ishida, H.; Koenig, J. L. J. Colloid Interface Sci. 1980, $74,396$. 

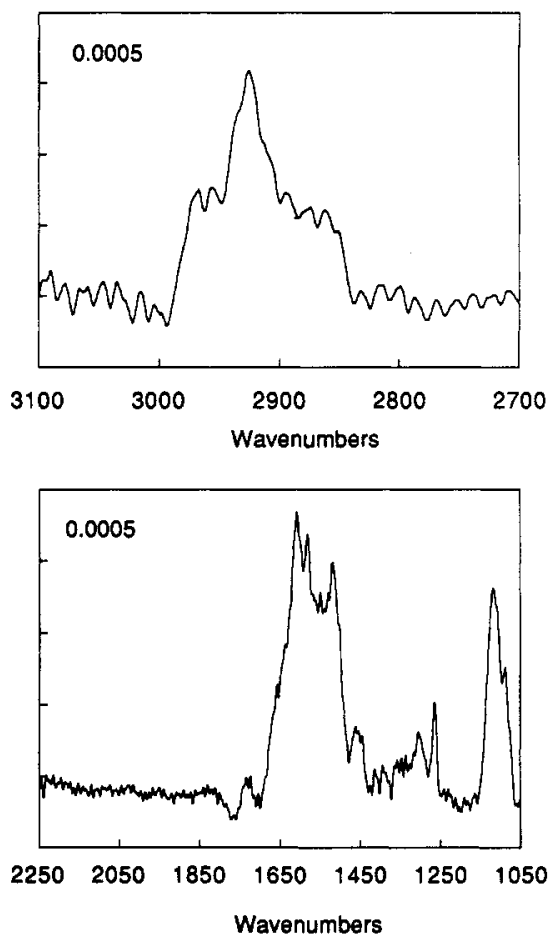

Figure 3. RAIR spectrum of an APS monolayer on oxidized aluminum (method I).

Table II. Band Positions and Assignments for APS

\begin{tabular}{|c|c|c|}
\hline $\begin{array}{l}\text { position } \\
\left(\mathrm{cm}^{-1}\right)\end{array}$ & assignment & lit. \\
\hline $\begin{array}{l}2970 \\
2926 \\
2900-2850\end{array}$ & $\begin{array}{l}-\mathrm{CH}_{3} \text {, asym str, } \mathrm{r}_{\mathrm{a}} \text {, shoulder (EtO-) } \\
-\mathrm{CH}_{2}-\text {, asym str, } \mathrm{d}^{-}(\pi) \\
{ }_{-\mathrm{CH}_{3} \text { sym str } \mathrm{r}^{+}(\mathrm{EtO}-)} \\
-\mathrm{CH}_{2}-\text { sym str } \mathrm{d}^{+}(\pi) \text { ip } \| \text { CCC-chain }\end{array}$ & $\begin{array}{l}2975^{28} \\
2925^{28 c} \\
\text { refs } 26,29\end{array}$ \\
\hline $\left.\begin{array}{l}1609 \\
1582 \\
1519\end{array}\right\}$ & $-\mathrm{NH}_{2}$, deformation (free, associated) & $1650-1550^{26 \mathrm{~b}}$ \\
\hline $\begin{array}{l}1455 \\
1390\end{array}$ & $\begin{array}{l}-\mathrm{CH}_{2}-\text {, def, (sci) ip \| CCC-chain } \\
-\mathrm{CH}_{3} \text {, sym def }\end{array}$ & $\begin{array}{l}1460^{26 a} \\
1380^{26 a}\end{array}$ \\
\hline 1264 & $\begin{array}{l}\text {-Si-CH }- \text {, def (wag) op } \delta(\pi) \| \\
\text { SiCC-plain }\end{array}$ & $1255^{24}$ \\
\hline $\left.\begin{array}{l}1118 \\
1089\end{array}\right\}$ & $\begin{array}{l}-\mathrm{Si}-\mathrm{O}-\mathrm{C}-(1100,1075) \\
-\mathrm{Si}-\mathrm{O}-\mathrm{Si}-(1150-1000)\end{array}$ & ref 24 \\
\hline
\end{tabular}

averaged over several QCM measurements ( $\delta f=48 \pm 2$ $\mathrm{Hz}$ ), is $5.3 \pm 0.2$ APS molecules $/ \mathrm{nm}^{2}$ (if the dominant species is $\mathrm{H}_{2} \mathrm{~N}\left(\mathrm{CH}_{2}\right)_{3} \mathrm{Si}(\mathrm{OEt})$ ) and the film thickness is 7 $\pm 1 \AA$. Both values correspond to a surface loading of about one monolayer. The higher surface loading of APS compared to MPS is attributed to the catalyzing effect of the amine group on the hydrolysis reaction. In a crosslinked film (method II), RAIR spectroscopy shows free amine groups. The surface loading appears slightly increased to $6.4 \pm 0.2 \mathrm{APS}$ molecules $/ \mathrm{nm}^{2}(\delta f=58 \pm 2 \mathrm{~Hz})$ and the film thickness is $11 \pm 2 \AA$. Within the errors of the experiment, this value is still associated with monolayer loading.

The intensities of the $\mathrm{CH}$ stretching modes in the RAIR spectra are in agreement with the ellipsometric data and support single layer formation. ${ }^{30}$ Figure 4 shows a representative calculation of the intensity of a $\mathrm{CH}$ stretch at $2950 \mathrm{~cm}^{-1}$ as a function of the film thickness for an isotropic layer on an aluminum oxide/aluminum substrate;

(30) The band intensities can be calculated by solving Maxwell's equations for the ambient/hydrocarbon/substrate interface. The resulting equations can be found in: Greenler, R. G. J. Chem. Phys. 1966, 44, 310 . The dielectric constant for the calculation was determined from a transmission spectrum (see ref 5 ).

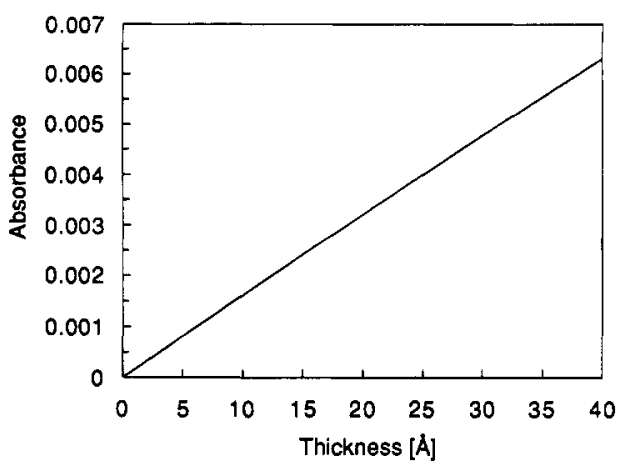

Figure 4. Calculated intensities for a $\mathrm{CH}$ stretch at $2950 \mathrm{~cm}^{-1}$ for the air/hydrocarbon/aluminum oxide/aluminum interface as a function of the film thickness for an isotropic layer $\left(n_{b}, 3.5-\right.$ i28.5; $n_{f}, 1.3-\mathrm{i} 0.1$, angle of incidence, $85^{\circ}$; wavelength, $\left.2950 \mathrm{~cm}^{-1}\right)$.

because of the varying oxide thicknesses the slope of the curve may vary from sample to sample. The refractive index for the substrate is obtained by calculating an effective index for the aluminum oxide/aluminum interface and the oxide film thickness determined by ellipsometry.

Monolayers of (3-Bromopropyl)trimethoxysilane (BPS) and (8-Bromooctyl)trimethoxysilane (BOS). Monolayers of BPS were prepared by vapor phase adsorption and subsequent heating of the film under dry nitrogen. The annealing step is necessary to initiate the chemisorption of BPS on the substrate. The formation of monolayers is not as reproducible as for APS and MPS. The film thickness varies between 9 and $16 \AA$. We attribute this to the fact that during the annealing process the surface bonding reaction, cross-linking, and desorption of BPS take place simultaneously.

Monolayers of BOS were prepared by adsorption from solution. The films were typically $15-18 \AA$ thick, which matches the projection of an extended octyl chain. The positions of the $\mathrm{CH}$ stretching modes at 2857 and 2927 $\mathrm{cm}^{-1}$ are identical to the solution values, which indicates that $B O S$ does not form ordered, all-trans assemblies. The silicon moiety in this film is mostly cross-linked, as indicated by the absence of the methoxy bands in the RAIR spectrum.

These films are not discussed in further detail because the subsequent reaction with cyanide did not occur (see below).

\section{Reactions of Immobilized Functional Groups}

Reaction of MPS Monolayer with Phenylmercury Hydroxide. The solution reaction of (3-mercaptopropyl)trimethoxysilane (MPS) with phenylmercury hydroxide occurs under mild conditions in methanol. ${ }^{31}$ The surface reaction was carried out by immersing the MPS-modified substrate in a solution of phenylmercury hydroxide in methanol for $15 \mathrm{~min}$.

The RAIR spectrum of the reaction of MPS with phenylmercury hydroxide is shown in Figure 5 . The band assignments and positions are summarized in Table III. The bands at 1603 and $1576 \mathrm{~cm}^{-1}$ are attributed to skeletal stretching of the monosubstituted phenyl nucleus. The transition dipole moments of both modes lie within the phenyl ring. Because of the high relative intensitities it can be concluded from the surface selection rules that the phenyl ring has an approximately upright orientation. The bands at $1477,1430,1377$, and $1295 \mathrm{~cm}^{-1}$ are attributed

(31) Bach, R.; Weibel, A. T. J. Am. Chem. Soc. 1976, 98, 6241. 


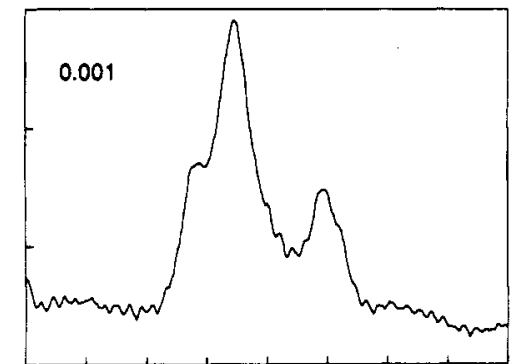

310030503000295029002850280027502700 Wavenumbers

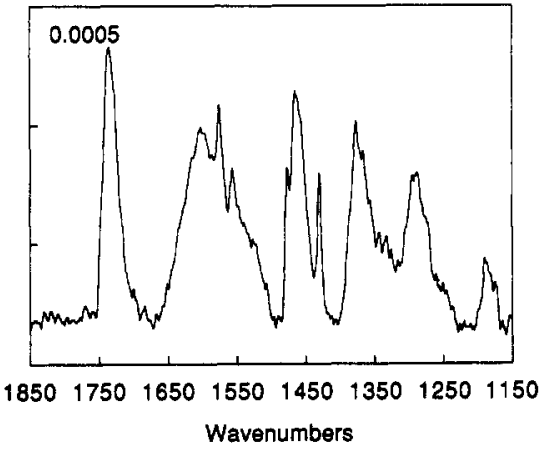

Figure 5. RAIR spectrum after the reaction of immobilized MPS and $\mathrm{PhHgOH}$.

Table III. Band Positions and Assignments for the Surface Reaction of MPS with PhHgOH

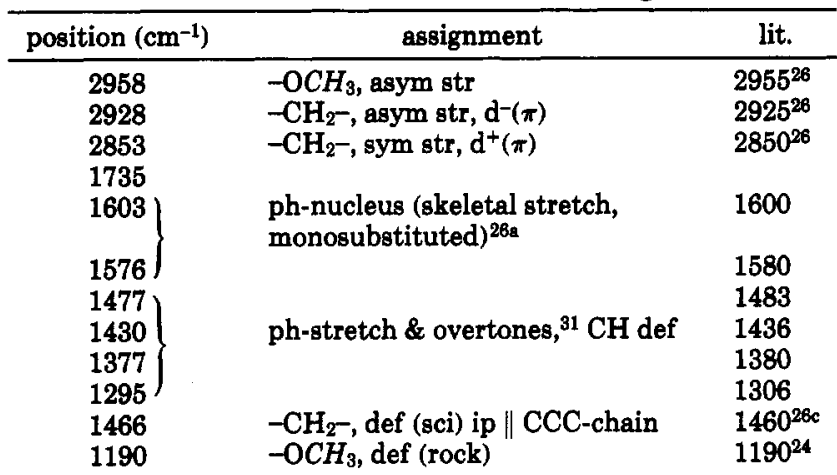

to skeletal stretching vibrations and overtones of the phenyl nucleus. ${ }^{32}$ The origin of the band at $1735 \mathrm{~cm}^{-1}$ has not been established yet. ${ }^{33}$ The band at $1466 \mathrm{~cm}^{-1}$ is assigned to the $\mathrm{CH}_{2}$ deformation vibration of the propyl group. The $\mathrm{Si}-\mathrm{CH}_{2}$ scissoring and wagging modes at 1260 and $1412 \mathrm{~cm}^{-1}$ disappear after the reaction, which indicates a structural rearrangement of the propyl group. The band at $1190 \mathrm{~cm}^{-1}$ is assigned to the $\mathrm{CH}$ rocking mode of the methoxy group.

The $\mathrm{CH}$ stretching vibrations of the phenyl ring, which are generally of low intensity, are not observed. The $\mathrm{CH}$ stretching region is dominated by the symmetric and asymmetric stretch at 2928 and $2858 \mathrm{~cm}^{-1}$ of the propyl group. From the changes in the $\mathrm{CH}$ stretching region it follows that the reaction is accompanied by a conformational rearrangement of the propyl group, in agreement with the changes in the $\mathrm{CH}$ deformation region. The shoulder at $2840 \mathrm{~cm}^{-1}$ and the strong shoulder at 2958 $\mathrm{cm}^{-1}$ are attributed to the symmetric and asymmetric $\mathrm{CH}$ stretching band of the methoxy group. From the stable

(32) Green, J. H. S. Spectrochim. Acta 1968, 24A, 863.

(33) This band could be due to an overtone of the phenyl ring or a carboxylic acid impurity; the transmission spectrum of phenylmercury hydroxide shows a band at $1760 \mathrm{~cm}^{-1}$. The acid shows bands between 1710 and $1750 \mathrm{~cm}^{-1}$ depending on the conditions of the measurement.
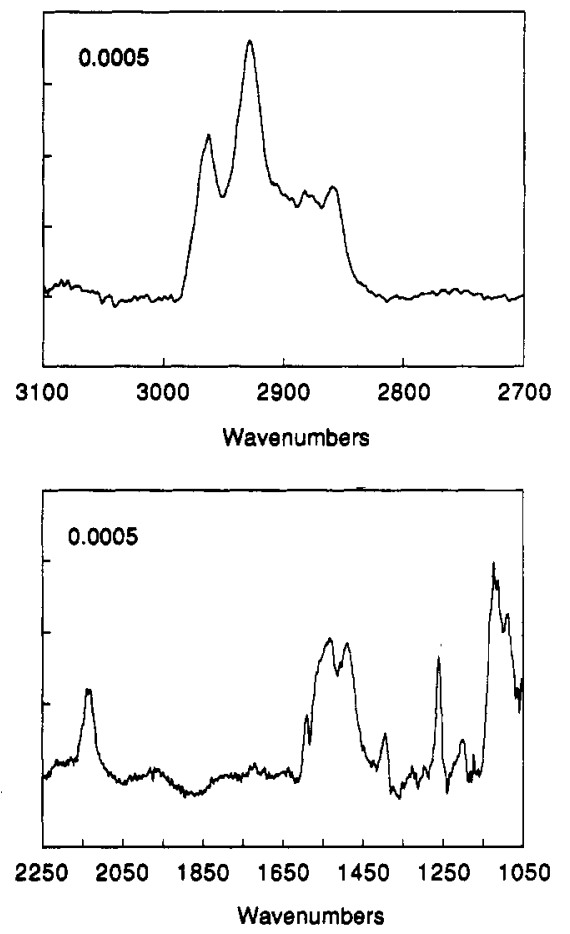

Figure 6. RAIR spectrum after the reaction of immobilized APS with $\mathrm{HSiClMe}$.

intensities of the methoxy bands it can be concluded that the degree of hydrolysis or condensation has not changed significantly during the course of the reaction.

The increase in the film thickness could not be precisely determined by ellipsometry, because the optical properties of the surface-anchored mercury compound are not known.

The advancing water contact angle increases from $57^{\circ}$ for the MPS film to $77^{\circ}$ after the reaction. The added hydrocarbon layer is expected to increase the hydrophobicity of the surface. However, the contact angle suggests a disordered overlayer structure, because ordered hydrocarbons have higher advancing water contact angles.

The ex situ QCM experiment monitoring the reaction of the immobilized mercapto groups with the phenylmercury hydroxide shows a frequency shift of $68 \pm 2 \mathrm{~Hz}$. From the RAIR analysis it follows that there is no evidence for solvent entrapment in the film. Furthermore, the water that is released during the reaction of the mercapto group with the phenylmercury hydroxide is not incorporated in the film. ${ }^{34}$ Thus, the frequency change is equivalent to an additional $3.5 \pm 0.3$ phenylmercury groups $/ \mathrm{nm}^{2}$. We conclude that within the error of the experiment all the mercapto groups immobilized on the surface $(3.2 \pm 0.2)$ per $\left(\mathrm{nm}^{2}\right)$ have reacted with the mercury reagent. No reaction of phenylmercury hydroxide with a blank aluminum slide occurred.

Reaction of APS Monolayers with Chlorodimethylsilane. It was found that the bulk reaction of (3aminopropyl)triethoxysilane with chlorodimethylsilane occurs readily to form the single adduct. The APSmodified substrate was exposed to the vapors of chlorodimethylsilane for $20 \mathrm{~min}$. The RAIR spectrum of the film after the reaction is shown in Figure 6. The total thickness of the sample after the reaction is $14 \pm 1 \AA$. This

(34) Methanol present in the film would show strong bands at 1033 $1449,2820,2942$, and around $3330 \mathrm{~cm}^{-1}$, and water would show broad bands around 1634 and $3400 \mathrm{~cm}^{-1}$. Ongoing research in our laboratory with QCM measurements indicates that diffusion in and out of these and other thin films occurs within seconds. 
Table IV. Band Positions and Assignments for the Surface Reaction of APS with $\mathrm{HSiClMe}_{2}$

\begin{tabular}{|c|c|c|}
\hline position $\left(\mathrm{cm}^{-1}\right)$ & assignment & lit. \\
\hline $\begin{array}{l}2962 \\
2929\end{array}$ & $\begin{array}{l}-\mathrm{Si}-\mathrm{CH}_{3} \text {, asym str } \\
-\mathrm{Si}-\mathrm{CH}_{3} \text { sym str } \\
-\mathrm{C}\end{array}$ & $\begin{array}{l}2964^{24 c} \\
2910^{24 a} \\
292526 a\end{array}$ \\
\hline 2880 & $-\mathrm{CH}_{3}$, sym stretch (EtO-) & $2870^{27}$ \\
\hline 2860 & $-\mathrm{CH}_{2}-\mathrm{sym}$ stretch & $2850^{26}$ \\
\hline 2139 & $\mathrm{Si}-\mathrm{H}$, stretch & $2100-2260^{34}$ \\
\hline 1591\} & $-\mathrm{NH}_{2}^{+}$, deformation & $1620-1520^{35}$ \\
\hline $1540^{\int}$ & & \\
\hline 1489 & $-\mathrm{CH}_{3}$, asym deformation & \\
\hline 1394 & $-\mathrm{CH}_{2}-\mathrm{NH}_{2}^{+}$, deformation & $\sim 1400^{26 \mathrm{c}}$ \\
\hline 1261 & $-\mathrm{Si}-\mathrm{CH}_{3}, \mathrm{Si}-\mathrm{CH}_{2}-$, deformation & $1255-60^{26 c}$ \\
\hline 1123) & $-\mathrm{Si}-\mathrm{O}-\mathrm{C}-,-\mathrm{Si}-\mathrm{O}-\mathrm{Si}-$ & \\
\hline 1092) & & \\
\hline
\end{tabular}

is in good agreement with the estimated length of a fully extended APS molecule and an additional dimethylsilane group.

The band assignments and positions are summarized in Table IV. The CH stretching region of the RAIR spectrum is dominated by the symmetric and asymmetric $\mathrm{CH}$ stretching mode of the newly attached $\mathrm{Si}-\mathrm{CH}_{3}$ moiety at $2962 \mathrm{~cm}^{-1}$ and around $2929 \mathrm{~cm}^{-1}$. The band at $2929 \mathrm{~cm}^{-1}$ interferes with the asymmetric $\mathrm{CH}$ stretching mode of the propyl group. The band at $2880 \mathrm{~cm}^{-1}$ is assigned to the symmetric $\mathrm{CH}_{3}$ stretch of the ethoxy group. The band at $2860 \mathrm{~cm}^{-1}$ is assigned to the symmetric $\mathrm{CH}$ stretching band of the propyl group. The band at $2139 \mathrm{~cm}^{-1}$ is characteriatic for the $\mathrm{Si}-\mathrm{H}$ stretch. This band is shifted approximately $40 \mathrm{~cm}^{-1}$ in comparison to neat chlorodimethylsilane $(2175$ $\mathrm{cm}^{-1}$, transmission IR). The shift is attributed to the changed electronic environment at the silicon after the substitution reaction, which confirms the substitution reaction versus a simple physisorption of the silane. ${ }^{35}$ The lower frequency region of the RAIR spectrum is dominated by the very characteristic mode of the $\mathrm{CH}$ deformation of $\mathrm{Si}-\mathrm{CH}_{2}$ and $\mathrm{Si}-\mathrm{CH}_{3}$ at $1261 \mathrm{~cm}^{-1}$. Salts of secondary amines show one to three NH deformation modes between 1520 and $1620 \mathrm{~cm}^{-1} .36$ The band at $1591 \mathrm{~cm}^{-1}$ and the broad band around $1540 \mathrm{~cm}^{-1}$ are therefore assigned to the protonated secondary amine group. The strongly enhanced band at $1394 \mathrm{~cm}^{-1}$ is characteristic for the $\mathrm{CH}_{2}$ deformation mode next to the $\mathrm{NH}_{2}{ }^{+}$group. The band at $1489 \mathrm{~cm}^{-1}$ is assigned to the asymmetric deformation mode of the $\mathrm{Si}-\mathrm{CH}_{3}$ group. The comparison of the $\mathrm{Si}-\mathrm{O}$ stretching region around $1100 \mathrm{~cm}^{-1}$ before and after the reaction shows that the degree of cross-linking has not changed significantly (Figures 3 and 5 ).

After the surface reaction with $\mathrm{HSiClMe}_{2}$, the water contact angle decreases from $52 \pm 2^{\circ}$ for the APS film to $41 \pm 3^{\circ}$. This result is surprising as the hydrophobic methyl groups of the silane moiety should reduce the wetting by water. In comparison, a blank aluminum substrate exposed to $\mathrm{HSiClMe}_{2}$ vapors shows a water contact angle of $50 \pm 1^{\circ}$. Thus, the lower contact angle of $41^{\circ}$ after the surface reaction of APS with $\mathrm{HSiClMe}_{2}$ supports the formation of an ammonium salt, as discussed above. The increased wetting is explained by either water penetration in the newly formed, disordered dimethylsilane overlayer ${ }^{37}$ or a yield of less than $100 \%$ and the surface composed of reacted groups with partially exposed ammonium groups (but see QCM data below).

(35) The $\mathrm{Si}-\mathrm{H}$ stretch varies in wide ranges, e.g. $2258 \mathrm{~cm}^{-1}$ for $\mathrm{HSiCl}_{3}$ and $2103 \mathrm{~cm}^{-1}$ for $\mathbf{E t}_{2} \mathrm{MeSiH}$ (see: Smith, A. L.; Angelotti, N. C. Spectrochim. Acta 1959, 15, 412).

(36) Heacock, R. A.; Marion, L. Can. J. Chem. 1956, 34, 1782.

(37) (a) Wilson M.; Ferguson, G.; Whitesides, G. M. J.Am. Chem. Soc. 1990, 112, 1244. (b) Bain, C.; Evan, J.; Whitesides, G. M. J. Am. Chem. Soc. 1989, 111, 7155 .
In principle the reaction of $\mathrm{HSiClMe}_{2}$ with the substrate cannot be ruled out. However, the RAIR spectrum of $\mathrm{HSiClMe}_{2}$ vapor adsorbed on oxidized aluminum shows $\mathrm{CH}$ stretch bands of approximately 20 times less intensity, indicating a low concentration of $\mathrm{HSiClMe}_{2}$ on the aluminum substrate. The corresponding changes of $\Delta$ and $\psi$ (ellipsometry) are within the error margin.

As mentioned earlier, the number of APS molecules was $5.3 \pm 0.2$ (I) and $6.4 \pm 0.2$ (II) molecules per $\mathrm{nm}^{2}$, depending on the experimental conditions. The APSmodified QCM crystal was exposed to the vapor of the reagent for $20 \mathrm{~min}$ and a steady increase in $\delta$ was observed. After evacuation the frequency stabilizes. The frequency change after the reaction is $33 \pm 2 \mathrm{~Hz}$ for sample $I$ and $42 \pm 3 \mathrm{~Hz}$ for sample II. Based on the data given above the frequency shift is equivalent to $5.3 \pm 0.2$ (I) and 6.6 \pm 0.4 (II) additional $\mathrm{HSiMe}_{2} \mathrm{Cl}$ molecules per $\mathrm{nm}^{2}$. It follows that within the experimental error the immobilized amino groups have stochiometrically reacted with the reagent.

Reaction of BPS and BOS Thin Films with Cyanide. In contrast to the observed reactivity of surfaceattached APS and MPS, it was not possible to substitute bromine in surface-anchored (3-bromopropyl)trimethoxysilane (BPS) and (8-bromooctyl)trimethozysilane (BOS) with cyanide, a reaction which occurs readily in the bulk phase. ${ }^{38}$ No reaction occurred after $12 \mathrm{~h}$ of refluxing with and without iodide as catalyst. The RAIR spectra do not show the CN stretch, typically a strong and characteristic band, after the reaction. Thin layers of (cyanopropyl)trimethoxysilane on gold show a moderately strong $\mathrm{CN}$ stretch at $2250 \mathrm{~cm}^{-1}$ in the RAIR spectrum. The CN stretch of the neat liquid is at $2246 \mathrm{~cm}^{-1}$ (transmission IR).

It is interesting to note that the advancing water contact angle is the same for both films, BPS and BOS, namely $82 \pm 1^{\circ}$. Bain and co-workers have found the water contact angle of 1-bromoundecanethiol on gold, a highly oriented monolayer, to be $83^{\circ} .2 \mathrm{~b}$ Although speculative, the similarity in the contact angles of the series BPS, BOS, and 1-bromoundecanethiol suggests that these films are comparable in the structure of the outer interfaces.

The operating mechanism for the bulk reaction is a $\mathrm{S}_{\mathrm{N}} 2$ substitution. It is a valid assumption that the interface reaction will proceed through a similar mechanism. Apparently there is not enough translational and rotational freedom in the surface layer for the reaction to occur, and the steric congestion at the bromoalkyl interface of BPS and $B O S$ inhibits the $S_{N} 2$ transition state at the surfaceanchored reaction center. Several surface reactions were carried out with different solvents and with different cyanide concentrations to rule out solvent, transport, or diffusion effects. Because iodide is very large, and is thus more sterically hindered, the reaction was also carried out uncatalyzed in a control experiment.

In an additional experiment immobilized BPS was reacted with 1.4-diazabicyclo[2.2.2] octane (DABCO), a very strong nucleophile. ${ }^{39}$ Even though BPS readily undergoes quaternization with $\mathrm{DABCO}$ in solution, no reaction was observed for the surface-attached species. However, immobilized APS reacted with 1,4-dibromobutane, although the primary amine is less nucleophilic. These additional data support the idea that steric congestion around the surface-confined transition state can present a barrier to a reaction.

(38) Organic Syntheses; Wiley: New York, 1988; Collect. Vol. VI.

(39) Abbiss, T. P.; Mann, F. G. J. Chem. Soc. 1964, 2248. 


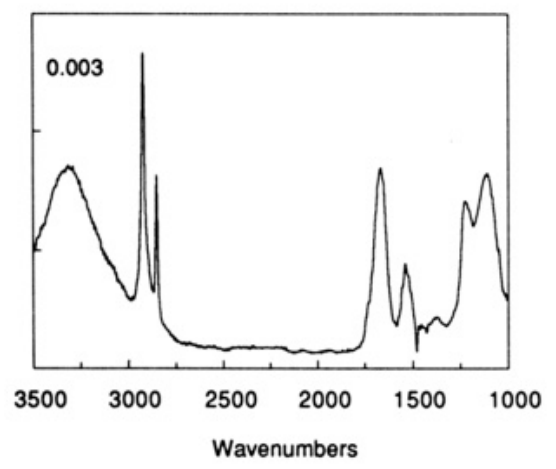

Figure 7. RAIR spectrum of pepsin immobilized with APS on oxidized aluminum.

Table V. Band Positions and Assignments for Pepsin

\begin{tabular}{cll}
\hline position $\left(\mathrm{cm}^{-1}\right)$ & \multicolumn{1}{c}{ assignment } & \multicolumn{1}{c}{ lit. $^{a}$} \\
\hline 3323 & -NH-, stretch (amide A) & $3100-3500$ \\
2922 & -CH-, asym str & 2925 \\
2852 & -CH-, sym str & 2850 \\
1669 & -C=0 str (amide I) & $1630-80$ \\
1540 & -NH-, def (amide II) & $1515-70$ \\
1228 & -NH-, def (amide III) & 1250 \\
1109 & -Si-O-, str & $1000-1100$ \\
962 & Al-0, str & 950
\end{tabular}

${ }^{a}$ Literature sources for these assignments are found in refs 26a and 41.

Immobilization of Pepsin. Pepsin was immobilized via the carbodiimide method on monolayers of APS. ${ }^{40}$ The RAIR spectrum of immobilized pepsin is shown in Figure 7. The band assignments and positions are summarized in Table V.

The band at $3323 \mathrm{~cm}^{-1}$ is assigned to the $\mathrm{N}-\mathrm{H}$ stretch (amide A) band. The bands at 2922 and $2852 \mathrm{~cm}^{-1}$ are assigned to the asymmetric and symmetric $\mathrm{CH}$ stretch. The band at $1669 \mathrm{~cm}^{-1}$ is attributed to the $\mathrm{C}=0$ stretch (amide I band). The amide II band is located at $1540 \mathrm{~cm}^{-1}$ and the amide III band is located at $1228 \mathrm{~cm}^{-1}$. These vibrations have been attributed to mixed $\mathrm{C}-\mathrm{N}$ and $\mathrm{N}-\mathrm{H}$ vibrations. ${ }^{41}$ The bands at 1109 and at $962 \mathrm{~cm}^{-1}$ are assigned to the $\mathrm{Si}-\mathrm{O}$ and $\mathrm{Al}-\mathrm{O}$ vibrations.

The frequency change due to chemisorbed pepsin on APS-modified QCM electrodes was $97 \mathrm{~Hz}$; the equivalent mass change is $470 \mathrm{ng} / \mathrm{cm}^{2}$. To remove physisorbed pepsin the QCM crystal was sonicated and dried until the frequency reading stabilized. With a molecular mass of $35000 \mathrm{~g} \mathrm{~mol}^{-1}$ the mass change is equivalent to a single layer of pepsin with an intermolecular spacing of approximately $35 \AA$. This compares well with the intermolecular spacing of pepsin in monolayers on water $(37 \AA)^{42}$ and in the solid state $(55 \AA \times 35 \AA \times 40 \AA) .{ }^{43}$ Even though the packing structures may differ to a certain extent, both comparisons support the attachment of a single pepsin layer with a $100 \%$ surface coverage.

\section{Conclusion and Outlook}

The reactions of monomolecular layers of (3-aminopropyl)triethoxysilane with chlorodimethylsilane, (3-mercaptopropyl)trimethoxysilane with phenylmercury hy-

(40) Line, W.; Kwong, A.; Weetall, H. Biochim. Biophys. Acta 1971, $242,194$.

(41) Koenig, J. L.; Tabb, D. L. In Analytical Applications of FT-IR to Molecular and Biological Systems; During, J. R., Ed.; Nato Advanced Study Institutes Series C57; D. Riedel Publishing Co.: Boston, MA, 1979.

(42) Langmuir, I.; Schaefer, V. J. Chem. Rev. 1939, 24, 181.

(43) Andreeva, N. S.; Fedorov, A. A.; Gushchina, A. E.; Shutskever, N. E.; Riskulov, R. R.; Volnova, T. V. Dokl. Akad. Nauk SSSR, 1976, 228, 480 .
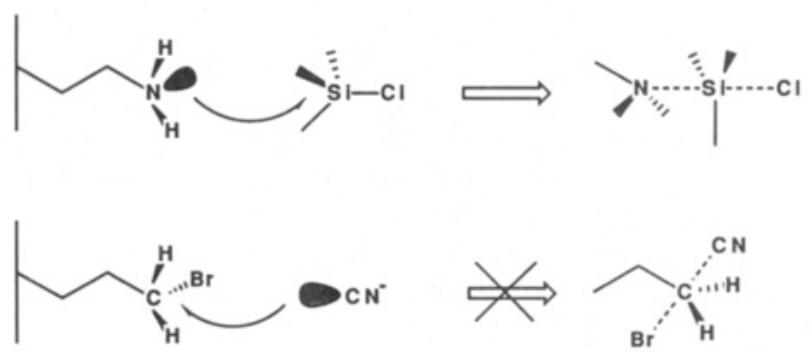

Figure 8. Transition states of the reaction of APS with chlorodimethylsilane and BPS with cyanide without implications on the nature of surface bonding. The amine in APS is the nucleophile and the incoming reagent reacts readily via a $S_{N} 2$ reaction. In the case of BPS the incoming cyanide is the nucleophile. The steric constraints on the reaction center located on the surface appear to prevent the reaction.

droxide, and (3-bromopropyl)trimethoxysilane and (8bromooctyl)trimethoxysilane with cyanide were investigated by reflection-absorption spectroscopy, ellipsometry, contact-angle measurements and the quartzcrystal microbalance. The RAIR spectra, the ellipsometric data and the QCM results show that the SCA's are present at approximately monolayer coverage. Pepsin was immobilized on monomolecular layers of APS. We demonstrate that the quartz-crystal microbalance is suitable for studies of surface reactions, including the adsorption of coupling agents and their subsequent reactions.

The gravimetric measurements indicate that the surface reactions of APS with chlorodimethylsilane and MPS with phenylmercury hydroxide are both approximately stoichiometric (within the limit of the experimental detection method). However, no substitution reaction of immobilized alkyl bromides with cyanide is observed, a reaction that occurs readily in solution. The reactions studied here can be grouped in two categories: (a) the reaction center is localized at the incoming reagent; (b) the reaction center is confined at the interface. In the first case, the transition state species does not experience steric limitations at the beginning of the reaction, because it does not have immobilized neighbors. In the second case, the reaction center is severely sterically encumbered because it is surrounded by immobilized neighbors. The congestion of the surface presents a barrier to the reaction; we did not find any spectroscopic evidence for a reaction (Figure 8). This suggests that for the first situation the yield of the reaction could in principle be less than $100 \%$, because toward the end of the reaction congestion of the surface could present the same barrier. In a recent study, Balachander and Sukenik have reported several $\mathrm{S}_{\mathrm{N}}$ 2 reactions at silane-attached functional groups, e.g., replacement of bromide in $\mathrm{Si} / \mathrm{SiO}_{2} / 1$-bromo-16-(trichlorosilyl)hexadecane by thiocyanate. ${ }^{44}$ Although different reactions were studied, their observation suggests that under certain deposition and/or reaction conditions the terminal bromide is not as encumbered as in the present case.

It becomes clear that reactivity encountered in solution may be inhibited in the surface-confined analog. Considering steric constraints, transport limitations, solvation effects, charge, and dipole effects on a surface during a reaction, this result is not so surprising. It will be important and interesting for future developments of surface-based chemistry to elucidate the effects of these factors in greater detail.

(44) Balachander, N.; Sukenik, C. N. Langmuir 1990,6,1621. No data on film thickness/coverage are given, thus it is possible that disorder in the films facilitates the substitution. 
Monolayers of APS have been shown to be efficient to immobilize pepsin. The bond between the enzyme and the surface is strong enough to withstand ultrasonic treatment. QCM measurements indicate that pepsin is bonded in a close packed fashion with an intermolecular spacing of only $35 \AA$. Such systems could serve well to simulate in vivo conditions in model membranes by utilizing mixed monolayers of enzymes and lipidlike molecules on surfaces.

\section{Experimental Part}

Materials. The silane coupling agents were obtained from Aldrich or Petrarch and were used as received. All the solvents were used as received. For the water contact angle measurements, HPLC grade water from Aldrich was used. For the adsorption experiments distilled water was used. The QCM were supplied from International Crystal Manufacturer (ICM, Oklahoma City).

Preparation of Aluminum Substrates. Glass slides were immersed in a "piranha" solution ( $7: 3$ concentrated $\mathrm{H}_{2} \mathrm{SO}_{4} / 30 \%$ $\mathrm{H}_{2} \mathrm{O}_{2}$ ) at $90^{\circ} \mathrm{C}$ for $1 \mathrm{~h}$, rinsed with distilled water, and blown dry with a strong flow of nitrogen. (Caution: "piranha" solution reacts violently with many organic materials and should be handled with extreme care.) Aluminum ( $99.999 \%$, Aldrich) was thermally or e-beam evaporated on the precleaned microscope glass slides (Fischer, $7.5 \mathrm{~cm} \times 2.5 \mathrm{~cm}$ ) at a base pressure of $5 \times$ $10^{-6}$ Torr. After evaporation the bell jar was purged with helium. The aluminum slides were stored in plastic boxes until used in experiments, generally as soon as possible. Prior to adsorption of the SCA the aluminum surfaces were cleaned in an oxygen or nitrogen plasma ${ }^{45}$ (Reytheon Microwave generator, McCarrol Coaxial chamber). In both cases a $30-80 \AA$ thin oxide layer is maintained as demonstrated by XPS and ellipsometry. Surfaces prepared in such a way showed no contamination in the RAIR and were totally wetted by water..$^{46}$ In some cases the slides were exposed to water vapor prior to the adsorption of the SCA. ${ }^{47}$ From SEM micrographs the average grain size on the surface was measured to be 100 to $150 \mathrm{~nm}$. The nitogen-adsorption isotherm of an aluminum-coated quartz-crystal microbalance shows that the aluminum surface has no significant porosity. ${ }^{48}$ An analysis of nitrogen isotherms of three different samples based on the BET method gave a surface area of $1.12 \mathrm{~cm}^{2} \mathrm{~cm}^{-2}$.

Reflection-Absorption IR Spectroscopy. Absorption spectra were obtained in the single reflection mode using a nitrogenpurged Mattson Polaris Fourier transform infrared spectrometer with a narrow band liquid nitrogen cooled MCT detector and a Harrick versatile reflection attachment. Best results were obtained by masking the beam with a $2 \mathrm{~mm}$ wide iris. The p-polarized light was incident at $86^{\circ}$. After triangular apodization the spectral resolution was $4 \mathrm{~cm}^{-1}$. The moving mirror velocity was $1.264 \mathrm{~cm} / \mathrm{s}$. One thousand scans were recorded. All spectra were reported in $-\log R / R_{0}$, where $R$ is the reflectivity of the sample and $R_{0}$ is the reflectivity of the reference slide. In some cases evaporated gold-on-glass slides instead of aluminum mirrors were used as reference surfaces. The spectra were usually corrected in the baseline. The band intensities were calculated according to ref 30; the film thicknesses derived from the RAIR band intensities and the ellipsometric data are in good agreement.

Ellipsometry. All measurements were taken on a manual Rudolf research ellipsometer equipped with a $\mathrm{HeNe}$ laser (632.8 $\mathrm{nm}$ ). The complex refractive index of the substrate was measured prior to the adsorption experiment. After the film formation the samples were again analyzed. The thickness was calculated with the refractive index of the bulk material and the previously

(45) O'Kane, D. F.; Mittal, K. L. J. Vac. Sci. Technol. 1974, 11, 567. (46) Schrader, M. In Surface Contamination: Genesis, Detection, and Control [Proceedings of a Symposium at the Fourth International Symposium on Contamination Control]; Mittal, K., Ed.; Plenum: New York, 1979; Vol. 2, p 541.

(47) (a) Vedder, W.; Vermilyea, D. A. Trans. Faraday Soc. 1969, 65, 561. (b) Thiel, P.; Madey, T. Surf. Sci. Rep. 1987, 7, 211.

(48) Lowell, S.; Shields, J. Powder Surface Area and Porosity, 2nd Ed.; Scarlett, B., Ed.; Chapman \& Hall: New York, 1984. measured index for the substrate using the three-phase model with an algorithm developed at Sandia National Laboratories (Tardy, H. L. Ellipse User's Manual and Program Reference; Report No. 89-0008; Sandia National Laboratories: Albuquerque, NM, 1989). The angle of incidence was $70^{\circ}$. All measurements were made taking 4-zone data. Several spots on the sample were measured. The transmission minimum was determined with the swing method. Several data points were taken and the null was interpolated from an azimuth, PMT signal curve fit. The calculated film thicknesses have typically an error of $\pm 1 \AA$.

Gravimetric Adsorption Measurements. The mass change upon adsorption was measured on polished AT-cut quartz crystal microbalances $\left(f_{\mathrm{o}}=9 \mathrm{MHz}, c_{\mathrm{f}} \sim 5.3 \mathrm{ngHz}^{-1} \mathrm{~cm}^{-2}\right)$ with aluminum electrodes with self-developed oscillator circuitry and a BK Precision Frequency Counter, Model 1803. Prior to the adsorption the crystals were cleaned in a nitrogen or oxygen plasma. The adsorptions were carried out under the same experimental conditions as the adsorption on the eluminum slides. The QCM was mounted with a plastic disk in a small glass vial that contained $0.5 \mathrm{~mL}$ of the SCA. All measurements were taken under nitrogen atmosphere or vacuum. Typically the vapor experiments were monitored in situ.

The QCMs were calibrated by the underpotential deposition (UPD) of a monolayer of copper on a gold electrode. ${ }^{49}$ The weight of the copper film and the calculated weight from the frequency shift with the Sauerbrey equation matched within $5 \%$. All reported values are corrected for a flat surface by taking into account the surface roughness. Several of the discussed preparation methods result in poorly reproducible film thicknesses; the variations are indicated in the respective sections. Thicknesses of representative monolayer films are given with the instrumental precision; the variations of the surface loadings of similar sample preparations are typically less than $\pm 15 \%$.

Wetting Measurements. Advancing water contact angles were determined with a self-built goniometer. The temperature was not controlled and varied between 20 and $25^{\circ} \mathrm{C}$. The atmosphere in the sample chamber was saturated with water vapor by filling the well of the chamber with water. The advancing contact angle was determined by lowering the needle to the surface and injecting $1 \mu \mathrm{L}$ of the liquid onto the surface. The drop would advance over the surface. The needle was raised. With this technique the contact angles were most reproducible. The tangent to the drop at its intersection with the surface was estimated visually. Both sides of the drop were measured and several spots on the sample were averaged. The measurement is accurate within $\pm 1^{\circ}$. Angles below $20^{\circ}$ were considered as total wetting. Typically contact angles were stable over a long period of time. Receding contact angles were not reproducible.

Adsorption of Silane Coupling Agents. The vapor-phase adsorptions were carried out in specially designed glass dishes of $8.5 \mathrm{~cm} \times 3.5 \mathrm{~cm}$. A $200-500-\mu \mathrm{L}$ portion of the SCA was dropped at the bottom of the dish with an Eppendorf pipet under nitrogen. The slide to be modified was immediately deposited onto the dish with the aluminum side facing the SCA. The adsorption was carried out under dry nitrogen, or in a humid environment, by placing a drop of water on the blank side of the slide, or under ambient atmospheric conditions ( $25 \%$ relative humidity). Adsorption times varied from several minutes to several hours. The slides were evacuated ( $10^{-3}$ Torr, molecular sieve pump) and purged with nitrogen to remove an excess layer on physisorbed material. Samples were also heated at $80^{\circ} \mathrm{C}$ under nitrogen after adsorption of the SCA to further complete the surface attachment.

Monolayers of MPS were prepared by adsorption from the vapors above an aqueous MPS solution. For this purpose of drop of water was added to the neat MPS.

Reaction of (3-mercaptopropyl)trimethoxysilane with Phenylmercury Hydroxide. To a warm solution $\left(35-45^{\circ} \mathrm{C}\right)$ of phenylmercury hydroxide $(1 \mathrm{~g}, 3.4 \mathrm{mmol})$ in methanol $(100$ $\mathrm{mL})$, (3-mercaptopropyl)trimethoxysilane $(0.66 \mathrm{~g}, 3.4 \mathrm{mmol})$ was dropped, and the mixture was stirred for $30 \mathrm{~min}$. The solvent was stripped off and a white-yellow oil was recovered. IR (liquid): $1104 \mathrm{~cm}^{-1}$ (b, s, str Si-O), $1191 \mathrm{~cm}^{-1}$ (s, s, d CH $\mathrm{CH}_{3}$, 1245

(49) Manne, S.; Hansma, P. K.; Massie, J.; Elinds, V. B.; Gewirth, A. A. Science 1991, 251, 183. 
$\mathrm{cm}^{-1}(\mathrm{~s}, \mathrm{~m}), 1301 \mathrm{~cm}^{-1}$ (s, w), $1340 \mathrm{~cm}^{-1}(\mathrm{~s}, \mathrm{w}), 1411 \mathrm{~cm}^{-1}(\mathrm{~s}, \mathrm{w})$, $1429 \mathrm{~cm}^{-1}$ (s, m), $1455 \mathrm{~cm}^{-1}$ (s, m), $1477 \mathrm{~cm}^{-1}(\mathrm{~s}, \mathrm{~m}), 1578 \mathrm{~cm}^{-1}$ (s, m), $2840 \mathrm{~cm}^{-1}$ (s, s, sym str $\left.\mathrm{CH}_{3}\right), 2941 \mathrm{~cm}^{-1}$ (b, s, str $\mathrm{CH}_{2}$ ), $3046 \mathrm{~cm}^{-1}$ (s, w, str CH), $3062 \mathrm{~cm}^{-1}$ (s, w, str CH).

The MPS-modified slide and QCM's were immersed in a solution of phenylmercury hydroxide $(0.5 \mathrm{~g}, 1.7 \mathrm{mmol})$ in methanol $(25 \mathrm{~mL})$ and stirred for 30 min at room temperature. Best results were obtained when prior to the reaction the QCM was immersed in methanol for $15 \mathrm{~min}$, purged, and dried in vacuum until a stable frequency reading was obtained. After the reaction the QCM was rinsed in methanol and dried in vacuum until the frequency reading was stable.

Reaction of (3-Aminopropyl)triethoxysilane with Chlorodimethylsilane. A $0.5-\mathrm{g}(2.3 \mathrm{mmol})$ portion of (3-aminopropyl)triethoxysilane (APS) was stirred in toluene with $0.45 \mathrm{~g}(5.0$ $\mathrm{mmol}$ ) of chlorodimethylsilane at room temperature for $30 \mathrm{~min}$ under nitrogen. The white precipitate was filtered off, washed with toluene and methanol, and dried at $90^{\circ} \mathrm{C}$. IR ( $\mathrm{KBr}$ pellet): $1100 \mathrm{~cm}^{-1}(\mathrm{~b}, \mathrm{~s}, \mathrm{str} \mathrm{Si}-0), 1251 \mathrm{~cm}^{-1}(\mathrm{~s}, \mathrm{~m}), 1335 \mathrm{~cm}^{-1}$ (s, w), 1391 $\mathrm{cm}^{-1}$ (s, m, d CH$\left.)_{2}\right), 1444 \mathrm{~cm}^{-1}$ (s, w, d $\left.\mathrm{CH}_{2}\right), 1496 \mathrm{~cm}^{-1}$ (s, m), 1603 $\mathrm{cm}^{-1}$ (s, w, d NH), $2112 \mathrm{~cm}^{-1}$ (s, s, str Si-H), $2877 \mathrm{~cm}^{-1}$ (s, s, str $\left.\mathrm{CH}_{2}\right), 2910 \mathrm{~cm}^{-1}\left(\mathrm{~s}, \mathrm{~s}, \mathrm{sym}\right.$ st $\left.\mathrm{CH}_{3}\right), 2966 \mathrm{~cm}^{-1}$ (s, s, asym str $\left.\mathrm{CH}_{3}\right)$ [s, sharp; b, broad; s, strong; m, medium; w, weak]. The bands from 2000 to $2700 \mathrm{~cm}^{-1}$ are characteristic for secondary ammonium salts. APS reacts with $\mathrm{HSiClMe}_{2}$ under formation of a single adduct. $^{50}$

APS films were prepared using two different methods: (I) The aluminum substrate was plasma cleaned and directly exposed to APS vapor. After evacuation the frequency change, $\delta f$, averaged over several experiments, was $48 \pm 2 \mathrm{~Hz}$, which is equivalent to $5.3 \pm 0.3 \mathrm{APS}$ molecules per $\mathrm{nm}^{2}$. (II) After plasma cleaning the substrate was exposed to water vapor prior to the adsorption of APS. After evacuation the frequency change was $58 \pm 3 \mathrm{~Hz}$, which is equivalent to $6.4 \pm 0.4 \mathrm{APS}$ molecules per $\mathrm{nm}^{2}$.

The APS-modified slides and QCM's were exposed to the vapor of chlorodimethylsilane for $15 \mathrm{~min}$ at room temperature in a closed glass container under nitrogen. After the reaction, the

(50) Campbell-Ferguson, H. J.; Ebsworth, E. A. V. J. Chem. Soc. A 1966, 1508. substrate was evacuated and purged with nitrogen. The samples were stored under nitrogen until all measurements were taken.

Reaction of (3-Bromopropyl)trimethoxysilane (BPS) and (8-Bromooctyl)trimethoxysilane (BOS) with Cyanide. One equivalent of the SCA was refluxed in dry ethanol for $4 \mathrm{~h}$ with 1.5 equiv of $\mathrm{NaCN}$ and a few $\mathrm{mg}$ of $\mathrm{NaI}$ as catalyst. The solution was filtered and the ethanol was stripped off. The crude oil was distilled. IR (liquid): $781 \mathrm{~cm}^{-1}, 936 \mathrm{~cm}^{-1}, 1100 \mathrm{~cm}^{-1}(\mathrm{~b}, \mathrm{~s}, \mathrm{Si}-0$ str), $1188 \mathrm{~cm}^{-1}$ (s, s, Si-O-C str), $1251 \mathrm{~cm}^{-1}$ (s, m, SiCH 2 def), $1391 \mathrm{~cm}^{-1}$ (s, w), $1425 \mathrm{~cm}^{-1}$ (s, m, CH def), $2246 \mathrm{~cm}^{-1}$ (s, s, CN str), $2888 \mathrm{~cm}^{-1}, 2934 \mathrm{~cm}^{-1}, 2975 \mathrm{~cm}^{-1}$.

The BPS and BOS modified slides were immersed in different solutions, including ethanol, DMSO, or glycol with $\mathrm{NaCN}$ or $\mathrm{KCN}$ and alternatively with a trace of $\mathrm{NaI}$ as catalyst at different concentrations, temperatures, and times. No surface reaction occurred even after $12 \mathrm{~h}$, with and without catalyst. Equivalent control experiments carried out in bulk were successful.

Immobilization of Pepsin. The APS-modified slides were stirred in a freshly prepared solution (A) of $50 \mathrm{~mL}$ of water, 0.4 $\mathrm{g}$ of pepsin, and $0.32 \mathrm{~g}$ of 1-cyclohexyl-3-(2-morpholinoethyl)carbodiimide [2491-17-0] at room temperature for $12 \mathrm{~h}$. The slides were rinsed with water, sonicated, and dried under vacuum.

The APS-modified QCM's were immersed in water for $1 \mathrm{~h}$ and dried under vacuum until the frequency stabilized. Then the QCM was immersed in solution A for $12 \mathrm{~h}$, rinsed with water, sonicated, and dried under vacuum until a stable frequency reading was found.

Acknowledgment. We thank Dr. Li Sun for help with the electrochemical experiments. The ellipsometric measurements were obtained on an instrument at the Center for High Technology Materials at the University of New Mexico. The authors acknowledge support for this work from the National Science Foundation (DMR-8706167 and DMR-900695) and from the Department of Energy (New Mexico WERC Program).

Supplementary Material Available: Raw QCM data for APS vapor adsorption and MPS/water vapor adsorption and raw RAIR spectra (6 pages). Ordering information is given on any current masthead page. 